\title{
Feasibility of a telephone and web-based physical activity intervention for women shift workers
}

\author{
S. E. Neil-Sztramko, PhD, ${ }^{1}$ C. C. Gotay, PhD, ${ }^{2,3}$ C. M. Sabiston, PhD, ${ }^{4}$ P. A. Demers, PhD, 5,6 \\ K. C. Campbell, BSc PT PhD ${ }^{3,7}$
}

${ }^{1}$ School of Nursing,

McMaster University, Hamilton,

Canada

${ }^{2}$ School of Population and Public Health,

University of British Columbia, Vancouver, Canada

${ }^{3}$ Center of Excellence in Cancer Prevention,

University of British Columbia,

Vancouver Canada

${ }^{4}$ Faculty of Kinesiology \& Physical

Education,

University of Toronto, Toronto,

Canada

${ }^{5}$ Dalla Lana School of Public Health, University of Toronto, Toronto,

Canada

${ }^{6}$ Occupational Cancer Research Centre, Cancer Care Ontario, Toronto, Canada

${ }^{7}$ Department of Physical Therapy, University of British Columbia, 212, Friedman Building, 2177 Wesbrook Mall Vancouver BC V6T 173 Canada Correspondence to: $\mathrm{K}$ Campbell kristin.campbell@ubc.ca

Cite this as: TBM 2017;7:268-276 doi: 10.1007/s13142-017-0471-7

(C) Society of Behavioral Medicine 2017

\section{INTRODUCTION}

Shift work (an occupation requiring work between 2200 and $0500 \mathrm{H}$ ) comprises approximately $20 \%$ of the workforce in Europe and North America [1]. This is likely to increase, with many shift workers (SWs) in emergency services, retail, hospitality, healthcare, transportation and manufacturing [2]. SWs are at increased risk for negative health outcomes, including cancer and other chronic diseases [3, 4]. Biological changes from poor lifestyle habits related to shift work (e.g. low physical activity (PA), poor nutrition, obesity) are thought to contribute to this risk; these factors are also amenable to lifestyle intervention [5]. PA in particular, reduces cancer risk [6], and has many positive physical and psychological benefits [7]. It is a simple, cost-effective strategy that may be implemented by individual workers or within workplaces to mitigate risk.

Unfortunately, SWs are unlikely to engage in regular PA [8]. In Canada, only $15.9 \%$ of SWs meet the PA guidelines and have lower levels of aerobic fitness than those of day workers [9]. Few behavioural interventions improving health outcomes in SWs have been published [10]. In a targeted PA intervention, nurses randomised to 4 months of supervised PA improved aerobic fitness, muscular strength, fatigue and musculoskeletal symptoms. However, authors reported low adherence and large loss to follow-up, perhaps due to the supervised scheduled sessions [11, 12].

Sustained behaviour change is a challenge and requires targeted efforts to encourage individuals to reach an adequate dose of PA to change health outcomes [13]. Due to irregular schedules and time constraints, SWs may be less likely to adhere to a traditional supervised PA intervention with face-to-face behavioural support [12]. Women SWs cite work schedule interference and lack of time as PA barriers and report scheduling flexibility as the most important in PA [14]. This highlights the need for a creative and innovative programming to promote $\mathrm{PA}$ in SWs.

Distance-based interventions, in which individuals exercise independent of study staff or participants, may include telephone counselling and website or smart phone app-based technology.

\section{Implications:}

Policy:Workplaces with large numbers of shift workers may consider implementing strategies to help their workers become more active.

Research:Based on feasibility and preliminary efficacy, similar interventions should be evaluated using a randomised controlled trial to determine efficacy.

Practice:Targeted interventions aimed at increasing physical activity in shift workers are feasible to implement.

These interventions are highly flexible and may help overcome barriers related to timing and scheduling that are important for SWs. In a review of telephone-based PA interventions, 14 of 17 found evidence for behaviour change [15]. These may be a way to implement scalable, individuallytailored interventions in SWs. The primary objective of this study was to test the feasibility of a distance-based PA intervention in women SWs. Feasibility studies are important for establishing effective processes and understanding resources required before attempting a randomised controlled trial (RCT), in order to put forward interventions that are most likely to be efficacious [16]. As this work was funded by a grant to examine the role of lifestyle in reducing breast cancer risk in SWs, only women were included. A secondary objective was to conduct a preliminary evaluation of intervention efficacy, to estimate effect size for future studies.

\section{MATERIALS AND METHODS}

\section{Participants}

Women participants were recruited through human resource and union contacts in the nursing, emergency services, casinos and airport via paper 
and online worksite postings, email lists and from a list of previous shift work study contacts. Englishspeaking SWs with daily telephone/Internet access who worked/lived in Greater Vancouver were eligible. Shift work was defined $\geq$ five shifts/month with work between 2200 and $0500 \mathrm{H}$, for $\geq 3$ years [17]. Women were ineligible if they self-reported $>90 \mathrm{~min} /$ week of moderate-vigorous PA (MVPA) [18] or were deemed higher risk for PA: selfreported body mass index $(\mathrm{BMI}) \geq 40.0 .0 \mathrm{~kg} / \mathrm{m}^{2}$, pregnant, $>55$ years old or answered 'Yes' to questions on the physical activity readiness questionnaire (PAR-Q) [19]. Ethical approval was obtained, and all participants provided written informed consent.

\section{Study procedures}

Following a telephone eligibility screen, participants met in person with a PA coach (a graduate student in public health with previous experience in administering physical activity and behaviour change interventions) to provide informed consent and receive data collection materials. During this visit, study goals and protocols for data collection were explained, and participants were familiarised with the Fitbit website (http://www.fitbit.com) and app. Participants were given a Fitbit Flex (Fitbit, San Francisco, CA) to aid in activity tracking and self-monitoring. The Fitbit Flex is a wrist-worn device that monitors step counts, distance covered and active minutes and synchronises wirelessly to computers/smart phones. Participants were asked to download weekly PA counts and email these to the PA coach during the intervention to guide discussion in the behavioural counselling sessions. The Fitbit Flex was delivered, and the first behavioural counselling session was scheduled following data collection. Participants received no monetary incentives and did not keep the Fitbit Flex.

The intervention was guided by the Health Action Process Approach (HAPA) [20]. This model aims to change the behaviour through increasing self-efficacy for PA intention, planning and maintenance. It included eight individualised, semi-scripted, distance-based (choice of telephone or video-FaceTime/Skype) behavioural counselling sessions over 12 weeks, between 0600 and $2200 \mathrm{H}$. Weeks one to six covered self-monitoring, goal-setting, overcoming barriers, preventing lapses, preparing for independent PA, evaluation and planning. Booster sessions at weeks nine and 12 focused on evaluating achievement of goals, building self-efficacy and planning. The study goal was $150 \mathrm{~min} /$ week of MVPA in bouts of $>10$ min [21] (Table 1).

\section{Outcomes}

As the primary outcome was feasibility, a single-group pre-post design was used. Feasibility outcomes were chosen in accordance with recommendations [22, 23], namely demand, implementation and acceptability. Demand: all recruitment efforts were tracked, and the number of participants who contacted and were screened by study staff was recorded, along with reasons for ineligibility or refusal. Implementation: delivery mode, session duration, date and time and rescheduled sessions were recorded to understand staffing requirements. Questions, problems and solutions related to the Fitbit Flex, website or app, were recorded. Acceptability: participants who enrolled but failed to complete the study were defined as dropouts. We planned to contact dropouts to record reasons for non-participation, although we had no dropouts in this study. Adherence to behavioural counselling sessions was calculated as the number of sessions completed. Participants were asked to share Fitbit data weekly via email, using the Fitbit website; however, this was optional due to ethical concerns. Adherence to Fitbit use was calculated as the percentage of days the Fitbit Flex was worn in participants who shared their Fitbit data. Adherence could not be calculated for those who chose not to share this data with investigators. The study team came to consensus to define a non-wear day as one in which $<500$ steps was registered. Participants were asked to rank their satisfaction with the intervention (overall intervention, behavioural counselling sessions and strategies, Fitbit and software, mode of delivery) as not at all satisfied, not very satisfied, somewhat satisfied or very satisfied in an online open-ended questionnaire. Secondary outcomes: information on demographics, work and lifestyle were collected via online questionnaires at baseline to describe the sample (Table 1). The secondary outcomes were collected at baseline and 12 weeks. PA and sedentary times were measured in 15 s epochs using a waist-worn Actigraph GT3X+ accelerometer (Actigraph, Pensacola, FL) $24 \mathrm{~h}$ /day for 7 days [24]. Valid wear time was defined as $>10 \mathrm{~h}$ /day for $>4$ days, and Freedson's VM3 cutpoints were used in analyses [25]. Work hours were recorded to identify occupational PA. Participants self-reported purposeful MVPA, PA and sedentary time using the recent physical activity questionnaire (RPAQ) [26]. In those who shared Fitbit data, the number of weeks with $>150$ min of MVPA was calculated using the 'active'/"very active' minutes $(>3.0$ METs). The Fitbit Flex has been shown to both under and overestimate steps and energy expenditure (EE, $\mathrm{kcal} /$ day) compared to a waist-worn accelerometer [27-29] and overestimate EE compared to indirect calorimetry in a laboratory setting [30]. Because SW weeks do not fall into a typical Monday-Sunday calendar, activity data were also averaged over a 12-week study period.

Physical and mental health-related quality of life (HRQoL) was measured using the RAND-36 [31], a widely used and validated tool. Scores range from 0 to 100 with higher scores indicating better 


\begin{tabular}{|c|c|c|}
\hline Week & Title & Topics \\
\hline 1 & Introduction & $\begin{array}{l}\text { - Introduction to shift work study } \\
\text { - Understanding the benefits of increasing PA } \\
\text { and decreasing sedentary time, generally and } \\
\text { specifically for shift workers } \\
\text { - Using the Fitbit for self-monitoring }\end{array}$ \\
\hline 2 & Goal-setting & $\begin{array}{l}\text { - General goal-setting } \\
\text { - S.M.A.R.T. goals } \\
\text { - F.I.T.T principle }\end{array}$ \\
\hline 3 & Overcoming barriers & $\begin{array}{l}\text { - Identifying barriers } \\
\text { - Identifying strategies to overcome barriers } \\
\text { - Barriers and coping plan }\end{array}$ \\
\hline 4 & Preventing lapses & $\begin{array}{l}\text { - Laws of behaviour change } \\
\text { - Behaviour change } \\
\text { - Review previous goal and set new goal }\end{array}$ \\
\hline 5 & Independent PA preparation & $\begin{array}{l}\text { - Social support } \\
\text { - Environmental support } \\
\text { - Rewards }\end{array}$ \\
\hline 6 & Evaluation and planning & $\begin{array}{l}\text { - Monitoring behaviour } \\
\text { - Maintaining motivation } \\
\text { - Reassessment of goals } \\
\text { - Plan for PA over next } 3 \text { weeks }\end{array}$ \\
\hline 7 & No session & \\
\hline 8 & No session & \\
\hline 9 & Booster session & $\begin{array}{l}\text { - Review how PA has gone over the last } 3 \text { weeks } \\
\text { - Attitudes about change } \\
\text { - Personal control, self-efficacy, self-esteem } \\
\text { - Discuss barriers, plans to overcome }\end{array}$ \\
\hline 10 & No session & \\
\hline 11 & No session & \\
\hline 12 & Booster session & $\begin{array}{l}\text { - Review everything learned } \\
\text { - Plan for future continued PA } \\
\text { - Re-evaluate final goals } \\
\text { - Logistics for end of study testing }\end{array}$ \\
\hline
\end{tabular}

HRQoL. Self-reported sleep quality and quantity were captured using the Pittsburgh Sleep Quality Index (PSQI), a reliable and valid questionnaire [32] that has been used in SWs. The total score ranges from 0 to 21 and component scores from 0 to 3. Lower scores indicate better sleep quality, with $\geq$ five indicating a poor sleep. Validated screening questionnaires for restless legs syndrome [33] and sleep apnoea [34] were administered but were not confirmed by a physician.

\section{Data analysis}

Feasibility was defined a priori as meeting the target sample size $(n=20)$ in $<4$ weeks, $<10 \%$ loss to follow-up, $>75 \%$ adherence to behavioural counselling sessions, $>85 \%$ adherence to Fitbit Flex wear and $>75 \%$ of participants reporting 'very' or 'somewhat satisfied'. Failure to achieve feasibility goals would indicate that substantial modifications were needed to the design, protocol and/or intervention prior conducting a RCT. The secondary outcomes were analysed using descriptive statistics (mean, median, standard deviation and percentage), and the difference between baseline and end of study was tested using a paired sample $t$ test. Sample size was based on budgetary constraints.

\section{RESULTS}

The recruitment goal was met in 10 days, exceeding the goal of 4 weeks. In total, 128 women contacted study staff (Fig. 1). We are unable to determine how many women may have seen the advertisement. The most common reasons for ineligibility were $>90 \mathrm{~min} /$ week of MVPA or not SWs. Once the recruitment goal was reached, no further participants were screened, leaving 61 individuals on a wait list for future studies. Twenty women were enrolled (see Table 2).

All participants chose telephone behavioural counselling sessions over Skype or FaceTime. Sessions lasted an average of $12.9 \mathrm{~min}$ (range 3.1-32.1) (Table 3). The first booster session (seven) was most often rescheduled. Sessions were mostly scheduled Monday-Friday, with one session on a weekend. The 


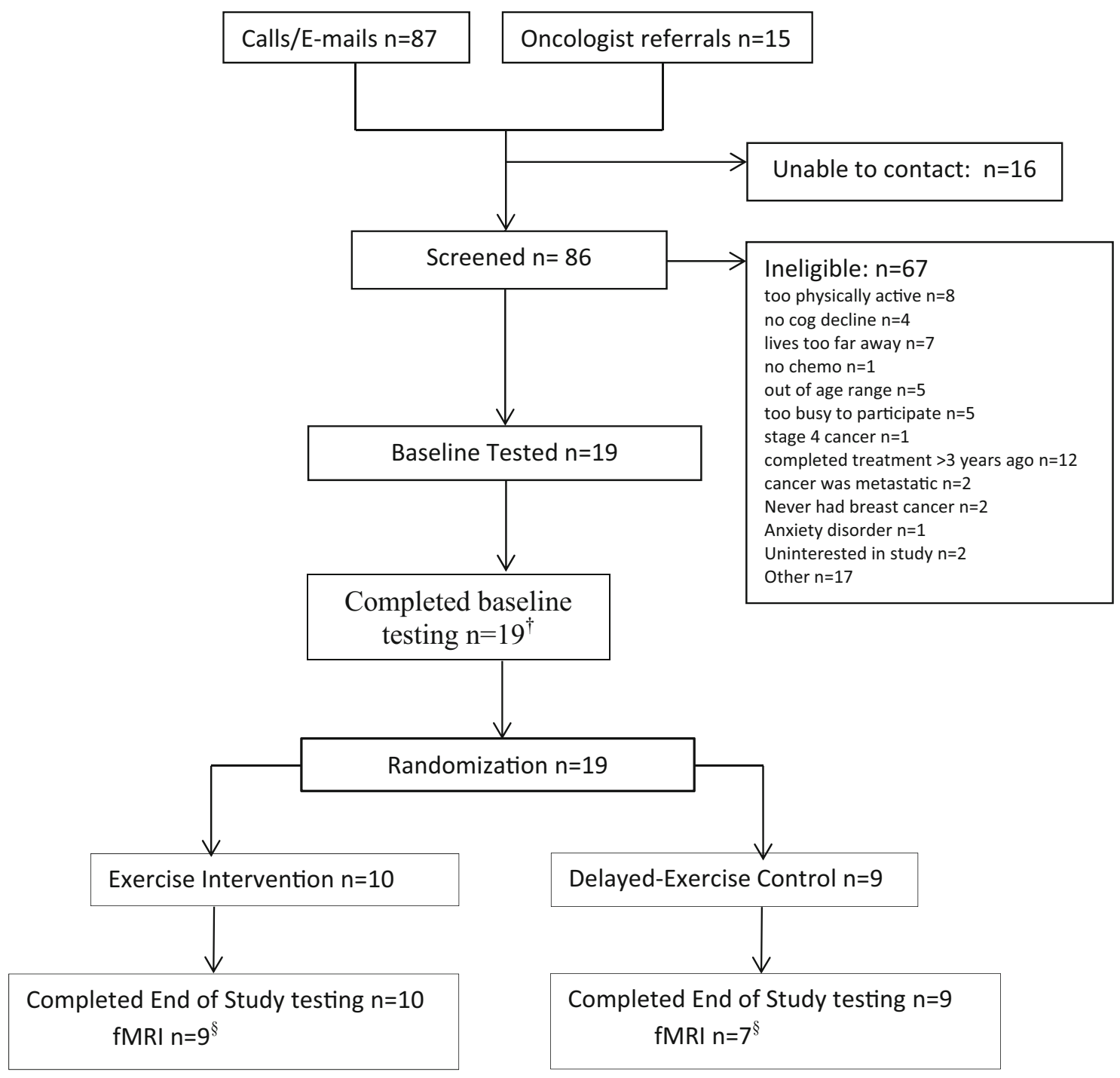

Legend: ${ }^{\dagger} n=2$ participants opted out of baseline fMRI; ${ }^{\S} n=3$ participants opted out of end of study fMRI

Fig. 1 | Participant recruitment and flow through the study

most common time for sessions was 0900-1200 h (52\%), followed by $1200-1700 \mathrm{~h}(39 \%)$, before $0900 \mathrm{~h}(7 \%)$ and $<1 \%$ of after $1700 \mathrm{~h}$.

During the study, five (25\%) Fitbit Flex's were returned (two stopped charging, three would not sync) and two were lost. Four participants contacted Fitbit telephone technical support. Participants reported frustration in that the Fitbit Flex was primarily a step-based tracker and did not track certain activities (ex. cycling, fitness classes) accurately.

Retention was $100 \%$, and no dropouts occurred. All participants completed baseline and 12-week questionnaires, and 19 (95\%) completed the participant satisfaction questionnaire. Two participants did not wear the accelerometer at 12-week data collection (too busy). Adherence to behavioural counselling sessions was $90.6 \%$ (mean $7.3 \pm 0.9$ sessions). All participants reported using the Fitbit Flex. Of the $18(90 \%)$ who shared Fitbit data, the Fitbit Flex was worn 94.5\% of the 84-day studsy period. One participant declined to share her data, and one participant used the Fitbit Flex as a daily monitoring tool and did not to sync to a computer or smart phone.

Participants were satisfied with the intervention (Table 4). In open-ended responses to the questionnaire, the most helpful components were accountability and motivation from participating $(n=7)$, awareness of PA from the Fitbit Flex $(n=4)$ and regular goal-setting or planning $(n=4)$. Future recommendations included connecting participants for added social support/accountability $(n=3)$, improving the Fitbit interface $(n=2)$ and increasing study duration $(n=2)$. 
Table 2 | Demographic characteristics of study participants $(n=20)$

\begin{tabular}{|c|c|c|}
\hline & Mean \pm SD & $N(\%)$ \\
\hline Age (years) & $42.2 \pm 8.6$ & \\
\hline Height $(\mathrm{cm})$ & $167.9 \pm 6.8$ & \\
\hline Weight (kg) & $78.7 \pm 15.5$ & \\
\hline Body mass index $\left(\mathrm{kg} / \mathrm{m}^{2}\right)$ & $27.7 \pm 4.2$ & \\
\hline \multicolumn{3}{|l|}{ Education } \\
\hline High school, some college or training school & & $2(10)$ \\
\hline College graduate or Bachelor's degree & & $17(85)$ \\
\hline Prefer not to answer & & $1(5)$ \\
\hline \multicolumn{3}{|l|}{ Marital status } \\
\hline Single, never married & & $4(20)$ \\
\hline Divorced or separated & & $3(15)$ \\
\hline Currently married or common-law & & $13(65)$ \\
\hline Full-time work schedule & & $17(85)$ \\
\hline Rotating shift work & & $19(95)$ \\
\hline Permanent shift work & & $1(5)$ \\
\hline \multicolumn{3}{|l|}{ Occupation } \\
\hline Nurse or care aide & & $17(85)$ \\
\hline Service industry & & $1(1)$ \\
\hline Airline industry & & $1(1)$ \\
\hline Communications & & $1(1)$ \\
\hline Shift work history (years) & $14.7 \pm 8.3$ & \\
\hline Number of night shifts per month & $7.6 \pm 4.4$ & \\
\hline Restless legs syndrome (self-report) & & $4(20)$ \\
\hline Sleep apnoea (self-report) & & $15(75)$ \\
\hline \multicolumn{3}{|l|}{ Chronotype } \\
\hline Morning & & $2(10)$ \\
\hline Evening & & $4(20)$ \\
\hline Middle & & $14(70)$ \\
\hline
\end{tabular}

A statistically significant increase in total objectively measured MVPA of $110.3 \mathrm{~min} /$ week was observed (Table 5). This was accompanied by a decrease in sedentary time of $405.5 \mathrm{~min} /$ week. There was no change in objectively measured MVPA in bouts of $>10 \mathrm{~min}$. Self-reported purposeful MVPA increased by $312.6 \mathrm{~min} /$ week, driven by increased leisure PA. Participants met the study goal $9.8 \pm 2.8$ weeks $(81.5 \%)$. When activity data were averaged over the entire study (rather than calculated weekly), 100\% of participants averaged $>150 \mathrm{~min} /$ week of MVPA. Participants lost an average of $0.9 \mathrm{~kg}$ of body weight $(p=0.03)$ (Table 6). Significant improvements in HRQoL were seen only in the energy/fatigue and emotional well-being domains. Significant improvements were found in sleep disturbances and day dysfunction due to sleepiness, but not total sleep (Table 6).

\section{DISCUSSION}

Based on our priori definition, this intervention was shown to be feasible implement in this population. Our recruitment goal was met quickly,

Table 3 | Duration of behavioural counselling sessions

\begin{tabular}{|c|c|c|c|c|}
\hline \multirow[t]{2}{*}{ Session } & \multicolumn{3}{|c|}{ Duration of session (min) } & \multirow{2}{*}{$\begin{array}{l}\text { Rescheduled sessions } \\
\%\end{array}$} \\
\hline & Mean & SD & Range & \\
\hline 1 & 14.2 & 5.8 & $5.7-26.2$ & 25 \\
\hline 2 & 16.7 & 6.8 & $6.9-32.1$ & 20 \\
\hline 3 & 13.6 & 6.1 & $6.5-26.1$ & 35 \\
\hline 4 & 12.6 & 5.3 & $6.8-22.0$ & 35 \\
\hline 5 & 13.5 & 6.9 & $5.8-27.7$ & 25 \\
\hline 6 & 13.0 & 5.6 & $5.2-27.6$ & 30 \\
\hline 7 & 12.1 & 4.3 & $6.4-21.2$ & 55 \\
\hline 8 & 7.6 & 3.4 & $3.1-13.8$ & 35 \\
\hline
\end{tabular}


Table 4 | Participant satisfaction $(n=19)$

Very/somewhat satisfied overall $16(84.2)$

Felt that study helped to increase physical activity $17(89.5)$

Very/somewhat satisfied with behavioural counselling session $16(84.2)$

Very/somewhat satisfied with Fitbit $15(78.9)$

Plan to purchase a Fitbit Flex or similar device $11(57.9)$

Would recommend intervention to a friend $18(94.7)$

Continued to exercise $150 \mathrm{~min} /$ week since study ended $17(89.5)$

Continued to use skills or strategies learned during the study $16(84.2)$

Made other lifestyle changes throughout intervention

showcasing the demand in this population and success with recruitment methods, particularly emails through employee lists. The most common reasons for ineligibility were current PA, not SWs, suggesting a demand exists for individuals on a variety of work schedules. Future studies could be expanded to include workers on a variety of different schedules, with modifications to the strategies used to meet individual needs. Despite a brief screen for PA via telephone, baseline PA was higher than $90 \mathrm{~min} /$ week, and four participants were already meeting PA guidelines at baseline. Future studies should consider more stringent eligibility screening to ensure they are recruiting participants who have the most to gain.

A variety of lessons were learned with respect to implementation. We anticipated that video sessions would be a popular choice to increase accountability. No participant chose this mode of communication for the behavioural counselling sessions, and all chose telephone delivery. Video conferencing may have been more challenging logistically for participants completing sessions on a lunch break from work, or may have felt too personal. These reasons should be explored in future studies. Sessions lasted an average of $12.9 \mathrm{~min}$, based on this, sessions in a larger trial could reasonably be booked in 30-min time slots. Participants often rescheduled sessions, either before the session or after a missed session. An online scheduling system, where participants could change their sessions in advance, with reminder emails or text messages may be useful to reduce the number of rescheduled sessions. Despite SWs' irregular schedules, they did choose to complete almost all sessions during Mon-Friday time slots, with the majority between 0900 and $1700 \mathrm{~h}$. This suggests that most sessions could be scheduled during regular working hours in future studies.

Technological Fitbit issues were the most common complaints. A higher than anticipated number of devices had to be returned for various

Table 5 | Change in objective and self-reported physical activity and sedentary time from baseline to end of study $(n=20)$

$$
\text { Baseline } \quad \text { End of Study } \quad \text { Change } \quad p
$$

Objectively measured activity, Actigraph GT3X+ accelerometer

\begin{tabular}{|c|c|c|c|c|}
\hline MVPA (min/week, bouts $\geq 10 \mathrm{~min})^{\text {a }}$ & $95.8 \pm 112.7$ & $101.8 \pm 103.7$ & -2.9 & 0.91 \\
\hline Work days & $38.3 \pm 62.6$ & $36.1 \pm 52.7$ & -2.4 & 0.81 \\
\hline Off days & $60.4 \pm 83.4$ & $65.7 \pm 60.5$ & +2.1 & 0.92 \\
\hline $\begin{array}{l}\text { Proportion meeting physical activity guidelines }{ }^{a} \mathrm{~N} \\
(\%)\end{array}$ & $4(20.0)$ & $5(27.8)$ & 0 & 0.99 \\
\hline MVPA (min/week, total) ${ }^{\text {a }}$ & $440.8 \pm 191.7$ & $551.5 \pm 165.1$ & +110.3 & $<0.01$ \\
\hline Steps per day ${ }^{a}$ & $7606.6 \pm 2912.9$ & $9145.9 \pm 2436.7$ & +1488.7 & $<0.01$ \\
\hline Sedentary time $(\min / \text { week, bouts } \geq 10 \mathrm{~min})^{\mathrm{a}}$ & $1510.5 \pm 654.8$ & $1136.7 \pm 317.1$ & -405.5 & 0.02 \\
\hline \multicolumn{5}{|c|}{ Self-reported activity, Recent Physical Activity Questionnaire } \\
\hline Purposeful MVPA (min/week) & $116.4 \pm 141.5$ & $429.0 \pm 270.7$ & +312.6 & $<0.001$ \\
\hline \multicolumn{5}{|l|}{ Total physical activity by domain (MET-hours/week) } \\
\hline Home & $9.2 \pm 6.2$ & $8.9 \pm 5.2$ & -0.3 & 0.73 \\
\hline Work & $45.7 \pm 16.4$ & $46.9 \pm 16.4$ & +1.2 & 0.50 \\
\hline Leisure & $2.7 \pm 2.5$ & $20.8 \pm 16.1$ & +18.1 & $<0.001$ \\
\hline Commute & $3.2 \pm 6.4$ & $4.2 \pm 6.0$ & +1.0 & 0.59 \\
\hline Sedentary time (min/week) & $2682.3 \pm 1151.44$ & $2257.0 \pm 1151.0$ & -425.3 & $<0.01$ \\
\hline
\end{tabular}


Table 6 | Change in self-reported efficacy outcomes from baseline to end of study

$\begin{array}{lll}\begin{array}{l}\text { Baseline } \\ \text { Mean } \pm \text { SD }\end{array} & \text { End of Study } & \text { Change }\end{array}$

\begin{tabular}{lllll} 
Body weight $(\mathrm{kg})$ & $78.7 \pm 15.5$ & $77.9 \pm 15.9$ & -0.9 & 0.03 \\
\hline Body mass index $\left(\mathrm{kg} / \mathrm{m}^{2}\right)$ & $27.7 \pm 4.2$ & $27.4 \pm 4.4$ & -0.3 & 0.04 \\
\hline Quality of life (RAND 36-item health survey) & & & & \\
\hline Physical functioning & $88.8 \pm 11.1$ & $90.8 \pm 14.2$ & +2.0 & 0.57 \\
\hline Role functioning/physical & $87.5 \pm 25.0$ & $92.9 \pm 16.7$ & +5.4 & 0.40 \\
\hline Role functioning/emotional & $70.0 \pm 38.8$ & $81.7 \pm 31.4$ & +11.7 & 0.11 \\
\hline Energy/fatigue & $46.7 \pm 16.8$ & $60.3 \pm 13.5$ & +14.6 & 0.01 \\
\hline Emotional well-being & $69.2 \pm 16.0$ & $79.0 \pm 10.1$ & +9.8 & 0.04 \\
\hline Social functioning & $80.0 \pm 22.0$ & $91.3 \pm 13.5$ & +11.3 & 0.06 \\
\hline Pain & $80.4 \pm 14.0$ & $80.9 \pm 12.3$ & +0.5 & 0.89 \\
\hline General health & $64.3 \pm 18.2$ & $72.8 \pm 14.3$ & +8.5 & 0.08 \\
\hline Sleep (Pittsburgh sleep quality index) & & & -1.2 & 0.16 \\
\hline Total score & $8.2 \pm 3.8$ & $7.0 \pm 3.9$ & +0.1 & 0.54 \\
\hline Duration of sleep & $0.7 \pm 0.7$ & $0.8 \pm 1.0$ & -0.2 & 0.04 \\
\hline Sleep disturbance & $1.5 \pm 0.6$ & $1.3 \pm 0.5$ & -0.4 & 0.09 \\
\hline Sleep latency & $1.6 \pm 1.2$ & $1.2 \pm 0.9$ & -0.4 & 0.04 \\
\hline Day dysfunction due to sleepiness & $1.2 \pm 0.5$ & $0.8 \pm 0.7$ & +0.2 & 0.49 \\
\hline Sleep efficiency & $1.1 \pm 1.3$ & $1.2 \pm 1.1$ & -0.3 & 0.20 \\
\hline Overall sleep quality & $1.3 \pm 0.7$ & $1.1 \pm 0.8$ & -0.3 & 0.14 \\
\hline Need meds to sleep & $0.9 \pm 1.1$ & $0.7 \pm 1.0$ & -3 & 0.45 \\
\hline Poor sleep quality (\%) & $14(70)$ & $11(55)$ & & \\
\hline
\end{tabular}

issues; this may explain why satisfaction was higher with behavioural counselling sessions than that of Fitbit. Because of this, a different type of activity tracker may be considered in the future, or a second in person education session following data collection could be added. Using the Fitbit Flex was burdensome to some who chose not to use the app, as they were not always on their computers every day to make it a useful motivating tool. For some, a simple pedometer may be just as effective at motivating behaviour change, and participants could be given a choice of trackers in future studies.

When only MVPA in bouts of $>10$ min was calculated, no change was observed during the study. However, sedentary time, total MVPA and self-reported PA improved significantly. This suggests that while overall PA increased, perhaps participants did not fit in planned sustained bouts of $>10 \mathrm{~min}$. In order to encourage a change in behaviour that is most likely to result in the greatest health benefits for participants, more emphasis should be placed on accumulating PA in bouts of at least $>10 \mathrm{~min}$ in future studies.

Several participants self-reported water or cyclebased activities, which are not captured well by accelerometers [35]; this may explain some lack of change and discrepancy between accelerometer and self-report. While self-report PA is subject to recall and self-report bias, it does overcome some accelerometer limitations by capturing all types of PA. A self-report questionnaire that captures the last 4 weeks of PA is also less influenced by one irregular week of PA, than those of accelerometers. While both have limitations, when accelerometer, RPAQ and Fitbit data are examined together, we believe participants did increase their overall levels of PA.

Interestingly, two thirds of participants reported making other lifestyle changes during the intervention. Despite no focus on weight loss in the present study, participants self-reported a small but statistically significant mean weight loss of approximately $1 \mathrm{~kg}$. While we hypothesise that this is due to increased PA, it may be the result of any dietary changes made by participants throughout the study, or may be due to chance. We did not collect any measures of dietary intake in this study, but this should be considered in the future. These findings suggest that a multi-pronged approach, perhaps by incorporating dietary, weight loss or sleep hygiene strategies, may capitalise on this opportunity for behaviour change; this should be explored in future studies.

A reduction in sleep disturbance and day dysfunction due to sleepiness was observed, although no change in total sleep quality was found. The reported reduction in daytime dysfunction may potentially be the result of increased in energy and vitality noted on the HRQoL questionnaire. PA has been shown to improve sleep [36, 37]; however, the exact frequency, intensity, duration and time of day of PA needed to optimally improve sleep are not known. While we did not examine the time of day that participants were physically active, it is an interesting area of future research. Higher levels of PA are associated with higher HRQoL in general population [38]. As shift 
work may adversely affect mental health [3], this may have important implications.

Several methodological limitations should be considered. The sample was small, based on a convenience sample of motivated participants, and comprised of primarily nurses or care aids, limiting generalisability. While this may indicate a stronger demand in this group, it is most likely a product of the recruitment strategy used. Changes may be needed before implementing in diverse occupational groups. The study took place in Vancouver, BC, a highly active city, where weather patterns are favourable for a variety of outdoor activities. Future studies should consider the seasonal effect of interventions on PA or may consider the development of specific behavioural counselling sessions with content for overcoming barriers specific to weather. As feasibility was the primary outcome, a single-group design was chosen to maximise the number of participants in the intervention. This limits our ability to attribute changes in outcomes to the intervention itself.

Behaviour change strategies informed by theories $[20,39]$, such as goal-setting, self-monitoring, feedback and social norms have consistently demonstrated efficacy in PA interventions [40]. Some studies have found that self-monitoring using the Fitbit is enough to elicit a positive behaviour change [41]; this is likely specific to highly motivated individuals. Others have found that more intensive intervention is needed. A meta-analysis of online health-promotion interventions found a positive correlation between effect size and the number of behaviour change strategies used [42]. A multi-armed intervention would be needed to tease out the independent and interactive effects of self-monitoring with the Fitbit from the behavioural counselling sessions.

This intervention, guided by the HAPA model, used several strategies to appeal to a variety of participants with different needs and barriers, while minimising time demands and participant burden. The distance-based approach using a passive tracking tool allowed for regular feedback and self-monitoring towards goals via the website or app. Sessions with the PA coach were brief, sometimes completed on work break, and helped with goal-setting and accountability. In open-ended questionnaires, participants reported an interest in completing this type of intervention with a friend or coworker. This could act to further enhance accountability and influence social norms and should be considered in the future. Based on these findings, a demand exists for PA interventions for SWs. This intervention was feasible to implement and may have a positive effect on PA, body weight, HRQoL and sleep. The next step is to implement the intervention on a wider scale, with a control group, and examination of biological markers linked to chronic disease risk to fully understand the changes that result from the intervention itself and to determine whether these changes in PA may lead to meaningful changes in chronic disease risk in SWs.

Acknowledgements: SENS was supported by a doctoral student award and a postdoctoral fellowship from the Canadian Institutes of Health Research. This project was also supported by an operating grant from the Canadian Cancer Society Research Institute (PI: CCG). The study sponsors had no role in the study design, collection, analysis and interpretation of data, writing of the report or decision to submit the paper for publication.

\section{Compliance with ethical standards}

Conflict of interest: The authors declare that they have no conflict of interest.

This manuscript has not been published elsewhere, nor has it been simultaneously submitted elsewhere. This work was part of a doctoral dissertation by lead author Sarah Neil-Sztramko. As such, part of this work is published in the doctoral dissertation published in the University of British Columbia's online dissertation repository. All authors have full control of all primary data and agree to allow the journal to review the data if requested. Ethical approval was provided by the University of British Columbia's Research Ethics Board, and all participants provided written informed consent.

\section{References}

1. IARC. (2007). Painting, fire-fighting and shiftwork. IARC monographs on the evaluation of carcinogenic risks to humans. Vol 98. IARC: Lyon.

2. Williams, C. (2008). Work-life balance of shift workers. Statistics Canada: Perspectives on Labour and Income, 9(8), 5-16.

3. Vogel, M., Braungardt, T., Meyer, W., \& Schneider, W. (2012). The effects of shift work on physical and mental health. J Neural Transm, 119(10), 1121-1132.

4. Wang, X. S., Armstrong, M. E., Cairns, B. J., Key, T. J., \& Travis, R. C. (2011). Shift work and chronic disease: the epidemiological evidence. Occup Med (Lond), 67(2), 78-89.

5. Fritschi, L., Glass, D. C., Heyworth, J. S., et al. (2011). Hypotheses for mechanisms linking shiftwork and cancer. Med Hypotheses, $77(3), 430-436$

6. World Cancer Research Fund / American Institute for Cancer Research. (2007). Food, nutrition, physical activity and the prevention of cancer: a global perspective. Washington, DC: AICR.

7. Reiner, M., Niermann, C., Jekauc, D., \& Woll, A. (2013). Long-term health benefits of physical activity-a systematic review of longitudinal studies. BMC Public Health, 13(1), 813.

8. Nabe-Nielsen, K., Quist, H. G., Garde, A. H., \& Aust, B. (2011), Shiftwork and changes in health behaviors. J Occup Environ Med, 53(12), 1413-1417.

9. Neil-Sztramko, S. E., Gotay, C. C., Demers, P. A., \& Campbell, K. L. (2016). Physical activity, physical fitness, and body composition of Canadian shift workers: data from the Canadian health measures survey cycles 1 and 2.J Occup Environ Med, 58(1), 94-100.

10. Neil-Sztramko, S. E., Pahwa, M., Demers, P. A., \& Gotay, C. C. (2014). Health-related interventions among night shift workers: a critical review of the literature. ScandJ Work Environ Health, 40(6), 543-556.

11. Harma, M. I., Ilmarinen, J., Knauth, P., Rutenfranz, J., \& Hanninen, O. (1988). Physical training intervention in female shift workers: II. The effects of intervention on the circadian rhythms of alertness, short-term memory, and body temperature. Ergonomics, 31(1), 5163.

12. Harma, M. I., Ilmarinen, J., Knauth, P., Rutenfranz, J., \& Hanninen, O. (1988). Physical training intervention in female shift workers: I. The effects of intervention on fitness, fatigue, sleep, and psychosomatic symptoms. Ergonomics, 37(1), 39-50.

13. Kahn, E. B. Ramsey, L. T., Brownson, R. C. et al. (2002). The effectiveness of interventions to increase physical activity: a systematic review. AmJ Prev Med, 22(4 Suppl), 73-107.

14. Neil, S. E., Muñoz, C., Beauchamp, M. R., Campbell, K. L., \& Gotay, C. C. (2013). Barriers to and preferences for physical activity in female shiftworkers (abstract). Sleep Science, 6(Supl 1), s61-s62. 
15. Goode, A. D., Reeves, M. M., \& Eakin, E. G. (2012). Telephonedelivered interventions for physical activity and dietary behavior change: an updated systematic review. AmJ Prev Med, 42(1), 81-88.

16. Bowen, D., Kreuter, M., Spring, B., et al. (2009). How we design feasibility studies. Am J Prev Med, 36(5), 452-457.

17. Gotay CC, Shen H, Muñoz C. A sleep intervention to improve quality of life (QoL) and sleep in shift workers at increased risk of breast cancer. International Society for Quality of Life Research Annual Conference; October 17, 2014, 2014; Berlin, Germany.

18. Campbell, K. L., Van Patten, C. L., Neil, S. E., et al. (2012). Feasibility of a lifestyle intervention on body weight and serum biomarkers in breast cancer survivors with overweight and obesity. $J$ Acad Nutr Diet, 112(4), 559-567.

19. Thomas, S., Reading, J., \& Shephard, R. J. (1992). Revision of the physical activity readiness questionnaire (PAR-Q). Can J Sport Sci, 17(4), 338-345.

20. Schwarzer, R., Lippke, S., \& Luszczynska, A. (2011). Mechanisms of health behavior change in persons with chronic illness or disability: the health action process approach (HAPA). Rehabil Psychol, 56(3), 161-170.

21. World Health Organization. Global recommendations on physical activity for health:18-64 years old. 2011.

22. Arain, M., Campbell, M. J., Cooper, C. L., \& Lancaster, G. A. (2010). What is a pilot or feasibility study? A review of current practice and editorial policy. BMC Med Res Methodol, 10, 67.

23. Thabane, L., Ma, J., Chu, R., et al. (2010). A tutorial on pilot studies: the what, why and how. BMC Med Res Methodol, 10, 1.

24. Santos-Lozano, A., Santin-Medeiros, F., Cardon, G., et al. (2013). Actigraph GT3X: validation and determination of physical activity intensity cut points. Int J Sports Med, 34(11), 975-982.

25. Sasaki, J. E., John, D., \& Freedson, P. S. (2011). Validation and comparison of ActiGraph activity monitors. J Sci Med Sport, 14(5), 411-416.

26. Besson, H., Brage, S., Jakes, R. W., Ekelund, U., \& Wareham, N. J. (2010). Estimating physical activity energy expenditure, sedentary time, and physical activity intensity by self-report in adults. $\mathrm{AmJ}$ Clin Nutr, 97(1), 106-114.

27. Dominick, G. M., Winfree, K. N., Pohlig, R. T., \& Papas, M. A (2016). Physical activity assessment between consumer- and research-grade accelerometers: a comparative study in freeliving conditions. JMIR Mhealth Uhealth, 4(3), e110.

28. Sushames, A., Edwards, A., Thompson, F., McDermott, R., \& Gebel, K. (2016). Validity and reliability of Fitbit flex for step count, moderate to vigorous physical activity and activity energy expenditure. PLoS One, 11(9), e0161224.

29. Reid RE, Insogna JA, Carver TE, et al. Validity and reliability of Fitbit activity monitors compared to ActiGraph GT3X+ with female adults in a free-living environment. J Sci Med Sport. 2016.

30. Bai, Y., Welk, G. J., Nam, Y. H., et al. (2016). Comparison of consumer and research monitors under semistructured settings. Med Sci Sports Exerc, 48(1), 151-158.

31. Hays, R. D., Sherbourne, C. D., \& Mazel, R. M. (1993). The RAND 36-item health survey 1.0. Health Econ, 2(3), 217-227.

32. Buysse, D. J., Reynolds 3rd, C. F., Monk, T. H., Berman, S. R., \& Kupfer, D. J. (1989). The Pittsburgh sleep quality index: a new instrument for psychiatric practice and research. Psychiatry Res, 28(2), 193-213.

33. Ferri, R., Lanuzza, B., Cosentino, F. I., et al. (2007). A single question for the rapid screening of restless legs syndrome in the neurological clinical practice. EurJ Neurol, 14(9), 1016-1021.

34. Netzer, N. C., Stoohs, R. A., Netzer, C. M., Clark, K., \& Strohl, K. P. (1999). Using the Berlin questionnaire to identify patients at risk for the sleep apnea syndrome. Ann Intern Med, 137(7), 485-491.

35. Trost, S. G., Mclver, K. L., \& Pate, R. R. (2005). Conducting accelerometer-based activity assessments in field-based research. Med Sci Sports Exerc, 37(11 Suppl), S531-S543.

36. Yang, P. Y., Ho, K. H., Chen, H. C., \& Chien, M. Y. (2012). Exercise training improves sleep quality in middle-aged and older adults with sleep problems: a systematic review. J Physiother, 58(3), 157-163.

37. Youngstedt, S. D. (2005). Effects of exercise on sleep. Clin Sports Med, 24(2), 355-365 xi.

38. Anokye, N. K., Trueman, P., Green, C., Pavey, T. G., \& Taylor, R. S. (2012). Physical activity and health related quality of life. BMC Public Health, 12, 624.

39. Bandura, A. (1977). Self-efficacy: toward a unifying theory of behavioral change. Psychol Rer, 84(2), 191-215.

40. Biddle, S., Hagger, M., Chatzisarantis, N., \& Lipple, S. (2007). Theoretical frameworks in exercise psychology. New York: Wiley.

41. Cadmus-Bertram, L. A., Marcus, B. H., Patterson, R. E., Parker, B. A., \& Morey, B. L. (2015). Randomized trial of a Fitbit-based physical activity intervention for women. Am J Prev Med, 49(3), 414-418.

42. Cugelman, B., Thelwall, M., \& Dawes, P. (2011). Online interventions for social marketing health behavior change campaigns: a meta-analysis of psychological architectures and adherence factors. J Med Internet Res, 13(1), e17. 